\title{
Thermo-catalytic pyrolysis of biomass and plastic mixtures using HZSM-5
}

\author{
Z. Sebestyén ${ }^{1}$, E. Barta-Rajnai ${ }^{1}$, J. Bozi $^{1}$, M. Blazsó ${ }^{1}$, E. Jakab ${ }^{1}$, \\ N. Miskolczi ${ }^{2}$, J. Sója ${ }^{2}$ and Zs. Czégény ${ }^{1 *}$ \\ ${ }^{1}$ Institute of Materials and Environmental Chemistry, Research Centre for Natural Sciences, \\ Hungarian Academy of Sciences, Magyar tudósok körútja 2, 1117 Budapest, Hungary \\ ${ }^{2}$ University of Pannonia, Institutional Department of MOL Hydrocarbon and Coal \\ Processing, Egyetem Street 10, 8201 Veszprém, Hungary
}
Z. Sebestyén
sebestyen.zoltan@ttk.mta.hu
E. Barta-Rajnai
rajnai.eszter@ttk.mta.hu
J. Bozi
bozi.janos@wardmaria.hu
M. Blazsó
blazso.marianne@ttk.mta.hu
E. Jakab
jakab.emma@ttk.mta.hu
N. Miskolczi
mnorbert@almos.uni-pannon.hu
J. Sója
sojajanos@almos.uni-pannon.hu
Zs. Czégény
czegeny.zsuzsanna@ttk.mta.hu

* Corresponding author. Tel.:+36-13826510

E-mail address: czegeny.zsuzsanna@ttk.mta.hu

Postal address: Magyar tudósok körútja 2, Budapest, H-1117, Hungary

\begin{abstract}
The catalytic effect of HZSM-5 zeolite was studied on the thermal decomposition of model waste mixtures of plastics (composed of PE, PP, and PET) and biomass (composed of newspaper, cardboard, and pine sawdust). The influence of temperature and catalyst ratio as well as the hindering effect of cellulose and lignin on the catalytic decomposition of plastic waste were studied applying analytical pyrolysis at low and high heating rate by thermogravimetry/mass spectrometry (TG/MS) and pyrolysis-gas chromatography/mass spectrometry (Py-GC/MS), respectively. The products of laboratory scale batch pyrolysis and
\end{abstract}


thermo-catalytic pyrolysis were analyzed in details and compared. HZSM-5 catalyst reduced the thermal stability of plastic waste, but the catalytic effect was blocked when $50 \%$ cellulose or $10 \%$ lignin were mixed in the plastic waste. Principal component analysis (PCA) has been applied to reveal correlations between the composition of pyrolysis products, pyrolysis temperature and proportion of the applied catalyst. It was established that the hindering effect of biomass could be compensated by applying higher catalyst ratio. In a batch reactor, the use of HZSM-5 catalyst led to a significant increase in the yields of volatiles (both gases and pyrolysis oil); moreover aromatization or isomerization effects have been observed. Aromatic compounds were produced to a reduced extent by thermo-catalytic pyrolysis of biomasscontaining plastic waste compared to that of plastic waste indicating that the cellulose and lignin components of the waste lower the HZSM-5 catalyst activity.

Keywords: catalytic pyrolysis; HZSM-5; plastic waste; biomass waste

\section{Highlights:}

- $\quad$ Pyrolysis of 3 model wastes was investigated in the absence and presence of HZSM-5.

- Effects of temperature, catalyst ratio and hindering effect of biomass were studied.

- $10 \%$ lignin or $50 \%$ cellulose hinders the catalytic activity of HZSM-5.

- Statistical analysis has been used to demonstrate correlations between the data.

- Results of analytical pyrolysis were used for suggesting conditions of batch pyrolysis.

\section{Introduction}

The increasing amount of municipal solid waste (MSW) is a serious environmental, social, and economic issue of the modern society. The European Union Waste Framework Directive (WFD) requires the reduction and utilization of municipal solid waste (MSW) prior to landfill disposal [1]. MSW is a multicomponent mixture, containing plastics, paper, wood and other organic and inorganic components. The separation technology of the MSW components from each other is very expensive or sometimes even beyond the possibilities. Pyrolysis is a promising waste-to-energy conversion method, which can be carried out via thermal or catalytic routes [2-7]. The thermal decomposition may result in undesirable products, depending on the raw material and the pyrolysis conditions. At high temperatures, polyaromatic compounds can be formed from plastics [8]. The thermal degradation of biomass-containing waste material results in high amount of heteroatom-containing 
molecules, which decrease the heating value, while increase the heterogeneity and hydrophilicity of the product. The quality of the pyrolysis oil can be improved by the addition of catalysts, where multiple reactions of cracking, deoxygenation, oligomerisation, aromatization, cyclization, alkylation, isomerization, and polymerization may take place in one reactor [2]. The main goals of the catalytic conversion are to reduce the relative amount of heteroatom containing molecules, to increase the heating value of the oil and to improve the stability during storage, or to decrease the pyrolysis temperature saving energy in this way. Several factors may influence the catalytic thermal decomposition of waste materials, such as temperature, heating rate, type of reactors, atmosphere, composition, and particle size of the feedstock, or the use of catalyst [9-12]. Different catalysts, such as ZSM-5, HZSM-5, Y-zeolite, FCC, $\mathrm{Fe}_{2} \mathrm{O}_{3}$ and transition metal oxides [13-15] have different impacts on the pyrolysis processes. HZSM-5 increases the volatility of the liquid products, and enhances the formation of aromatic hydrocarbons. Moreover, HZSM-5 has very low rate of deactivation and is suitable for reuse [16-17].

Many studies have been carried out on the catalytic thermal decomposition of different synthetic polymers, biomass materials and their various mixtures using thermogravimetric analysis (TGA) [18-22], pyrolysis-gas chromatography/mass spectrometry (Py-GC/MS) [2326] and laboratory scale batch reactor [27-30]. However, there is a lack of literature that is focused on experiments, which compare the analytical pyrolysis and laboratory scale batch pyrolysis results.

The aim of this work is to study the catalytic thermal decomposition of synthetic polymer biomass mixtures using TG/MS and Py-GC/MS techniques, and laboratory scale batch pyrolysis in order to clarify the thermal decomposition processes based on the complementary information obtained by the above methods. The effect of HZSM-5 catalyst on the decomposition temperature and the composition of pyrolysis products of plastics and biomass-plastics model waste mixtures were studied in order to understand the possible changes in the catalytic activity during the catalytic thermal conversion of waste mixtures into valuable products. 


\section{Materials and Methods}

\subsection{Materials}

The composition of the model waste mixtures is summarized in Table 1 . The mixtures were cryo-ground in a Retsch MM301 mill, to obtain homogenous samples for the analytical pyrolysis experiments. In the laboratory scale batch pyrolysis experiments, the particle size of the waste material was around $5-8 \mathrm{~mm}$. In order to understand the role of the biomass components in the thermal degradation process, mixtures containing cellulose (Whatman) and beech milled wood lignin were studied. The effects of the zeolite HZSM-5 catalyst were tested using 10:1 waste/catalyst ratios in both analytical pyrolysis and laboratory scale batch pyrolysis experiments. Under analytical pyrolysis conditions, the contact time of the pyrolysis vapors and the catalyst is low due to the low sample amount, and the relatively high gas flow rate, therefore additional experiments were performed using 1:1 waste/catalyst ratio to see the catalytic effect more pronouncedly. The used HZSM-5 catalyst had the following properties: $19 \mu \mathrm{m}$ average grain diameter, $330 \mathrm{~m}^{2} / \mathrm{g}$ BET surface, 0.55 mequiv of $\mathrm{NH}_{3} / \mathrm{g}$ acidity and $22 \mathrm{Si} / \mathrm{Al}$ ratio.

Table 1. Composition of the studied model waste mixtures

\begin{tabular}{llllll}
\hline \multicolumn{2}{l}{ Plastic waste } & \multicolumn{2}{l}{ Biomass waste } & \multicolumn{2}{l}{ Mixed waste } \\
\hline Composition & Polyethylene (PE) & $40 \%$ & Newspaper & $40 \%$ & Plastics $50 \%$ \\
$($ wt $\%)$ & Polypropylene (PP) & $40 \%$ & Cardboard & $40 \%$ & Biomass 50\% \\
& Polyethylene terephthalate (PET) 20\% & Pine sawdust 20\% & \\
\hline
\end{tabular}

\subsection{Methods}

\subsubsection{Thermogravimetry/mass spectrometry (TG/MS)}

TG/MS measurements were performed applying a modified Perkin-Elmer TGS-2 thermobalance and a HIDEN HAL 2/301 PIC mass spectrometer. Typically 0.5-4 mg samples were heated at a $20{ }^{\circ} \mathrm{C} \min ^{-1}$ heating rate up to $900{ }^{\circ} \mathrm{C}$ in argon atmosphere. A small proportion of the evolved gas and vapor was introduced into the MS through a glass lined metal capillary transfer line heated to $300{ }^{\circ} \mathrm{C}$ by argon gas using a flow rate of $140 \mathrm{~mL} \mathrm{~min}{ }^{-1}$. The ion source of the mass spectrometer was operated at $70 \mathrm{eV}$ electron energy. The mass range of 2-150 Da was scanned at every $25 \mathrm{~s}$ excluding the main ions of the argon carrier gas. The ion intensities were normalized to the sample mass and to the intensity of the ${ }^{38} \mathrm{Ar}$ 
isotope of the carrier gas. Under gradual heating the sample weight and ion intensity of the degradation products were monitored by a computer. The mass of the catalyst was subtracted from the sample weight, therefore the presented weight curves (TG curves) show the decomposition of the waste sample. Derivative curves of the TG curves (DTG) present the weight loss rate under gradual heating as a function of temperature.

\subsubsection{Pyrolysis-gas chromatography/mass spectrometry (Py-GC/MS)}

Py-GC/MS experiments were carried out using a Pyroprobe 2000 pyrolyzer interfaced to an Agilent $6890 \mathrm{~A} / 5973 \mathrm{GC} / \mathrm{MS}$. The amounts of 0.3-0.6 mg samples were pyrolyzed at 450 and $550{ }^{\circ} \mathrm{C}$ (calibrated temperatures) for $20 \mathrm{~s}$ in helium atmosphere. The pyrolysis products were separated on a DB-1701 capillary column $(30 \mathrm{~m} \times 0.25 \mathrm{~mm}, 0.25 \mu \mathrm{m}$ film thickness). The GC oven was programmed to hold at $50{ }^{\circ} \mathrm{C}$ for $1 \mathrm{~min}$ then increase the temperature at a rate of 10 ${ }^{\circ} \mathrm{C} \mathrm{min}{ }^{-1}$ to $280{ }^{\circ} \mathrm{C}$ (hold for $15 \mathrm{~min}$ ). The mass range of $\mathrm{m} / \mathrm{z}$ 14-500 was scanned by the mass spectrometer in electron impact mode at $70 \mathrm{eV}$.

\subsubsection{Principal component analysis}

Due to the high number of the samples, a chemometric tool, principal component analysis (PCA) has been used to carry out linear data reduction for the purpose of pattern visualization [31]. PCA has been applied to illustrate correlations between Py-GC/MS data of the samples. PCA transforms the original variables into new variables called principal components (factors). Each factor is uncorrelated (orthogonal) and is a linear combination of the original variables. The first principal component accounts for the maximum of total variance, the second is uncorrelated with the first and accounts for the maximum of residual variance, and so on. The results can be presented in a score plot and a loading plot. The values that denote the samples in the space defined by the principal components (factors) are the component scores. Factor loadings present the correlation between the original variables and the factors [31]. In this work, average mass spectra were generated from each pyrogram. The MS intensities of the 17 characteristic fragment and molecular ions were chosen for statistical assessment; representing aliphatics (e.g., $m / z$ 41, 43, 55, 70, 126), aromatics (e.g., $m / z$ 78, 91, 92, 106), biomass (e.g., $\mathrm{m} / \mathrm{z} 31,60,95,96)$, and PET $(\mathrm{m} / z$ 297) decomposition products. The results were presented in a score plot and a loading plot. 


\subsubsection{Laboratory scale batch pyrolysis}

Pyrolysis of model waste mixtures was also carried out in a stainless steel batch reactor (Fig. 1). Approximately $500 \mathrm{~g}$ samples were weighed into the reactor and $10 \%$ of HZSM-5 catalyst was added for thermo-catalytic pyrolysis. The temperature of the electrically heated reactor was adjusted by PID controller. The temperature of pyrolysis was $550{ }^{\circ} \mathrm{C}$. Nitrogen flushed the volatile products from the reactor at a constant flow rate $(5 \mathrm{~L} / \mathrm{h})$. The volatiles were driven through a water cooled heat exchanger, where the vapors condensed, and then the products were separated into the gas fraction and pyrolysis oil in a phase separator. The volume of the gases was measured by a gas flow meter (VEB Junkalor Dessau type), while the qualitative and quantitative analyses of the gases were performed by GC measurements. The condensed products were separated to water and pyrolysis oil, then the pyrolysis oil was treated by potassium-chloride to reduce the residual water content. The solid fraction contained the carbonaceous char and the catalyst. The amount of char was calculated by subtracting the amount of catalyst from the weight of the solid residue. One experiment was performed on each model waste mixture. The standard deviation of the yields was between $0.5 \%$ and $1.6 \%$ in previous repeatability tests.

The composition of hydrocarbon gases was determined by gas-chromatography (DANI type GC instrument with flame ionization detector). The used columns were Rtx PONA (100m x $0.25 \mathrm{~mm}, 0.5 \mu \mathrm{m}$ film thickness) and Rtx-5 PONA (100m x $0.25 \mathrm{~mm}, 1 \mu \mathrm{m}$ film thickness). The sample analysis was performed under isothermal conditions $\left(\mathrm{T}=30^{\circ} \mathrm{C}\right)$ for $30 \mathrm{~min}$. The temperatures of the injector and the detector were $240{ }^{\circ} \mathrm{C}$.

The carbon-oxides and hydrogen contents of the gaseous products were measured by gas chromatograph (Shimadzu GC-2010 equipped with TCD detector) applying a CarboxenTM 1006 PLOT column $(30 \mathrm{~m} \times 0.53 \mathrm{~mm})$. The temperature program was the following: from 35 ${ }^{\circ} \mathrm{C}$ (hold time $2 \mathrm{~min}$ ) to $250{ }^{\circ} \mathrm{C}$ at $40{ }^{\circ} \mathrm{C} \min ^{-1}$ heating rate, with the final temperature maintained for $5 \mathrm{~min}$. Gas mixtures of defined compositions were used for the calibration.

The pyrolysis oil was analyzed by DANI type GC instrument, using Rtx 1 column (30m x $0.53 \mathrm{~mm}, 0.25 \mu \mathrm{m})$.. The identification of the GC peaks was based on the retention time of standards. The quantitative data of the GC analyses are integrated peak area values of the gas chromatograms. 
The determination of densities, cloud points, and boiling points was performed by MSZ EN ISO 12185:1998, MSZ 11721:1964, and EN ISO 3405:2000, respectively.

The higher heating value (HHV) was determined using bomb calorimeter (Parr 6200). The combustion of about $0.5 \mathrm{~g}$ sample was performed in pure oxygen atmosphere under 20 bar pressure. Benzoic acid calibration was applied to determine the heat capacity of the calorimeter. All heating values were calculated from the averages of three replicates.

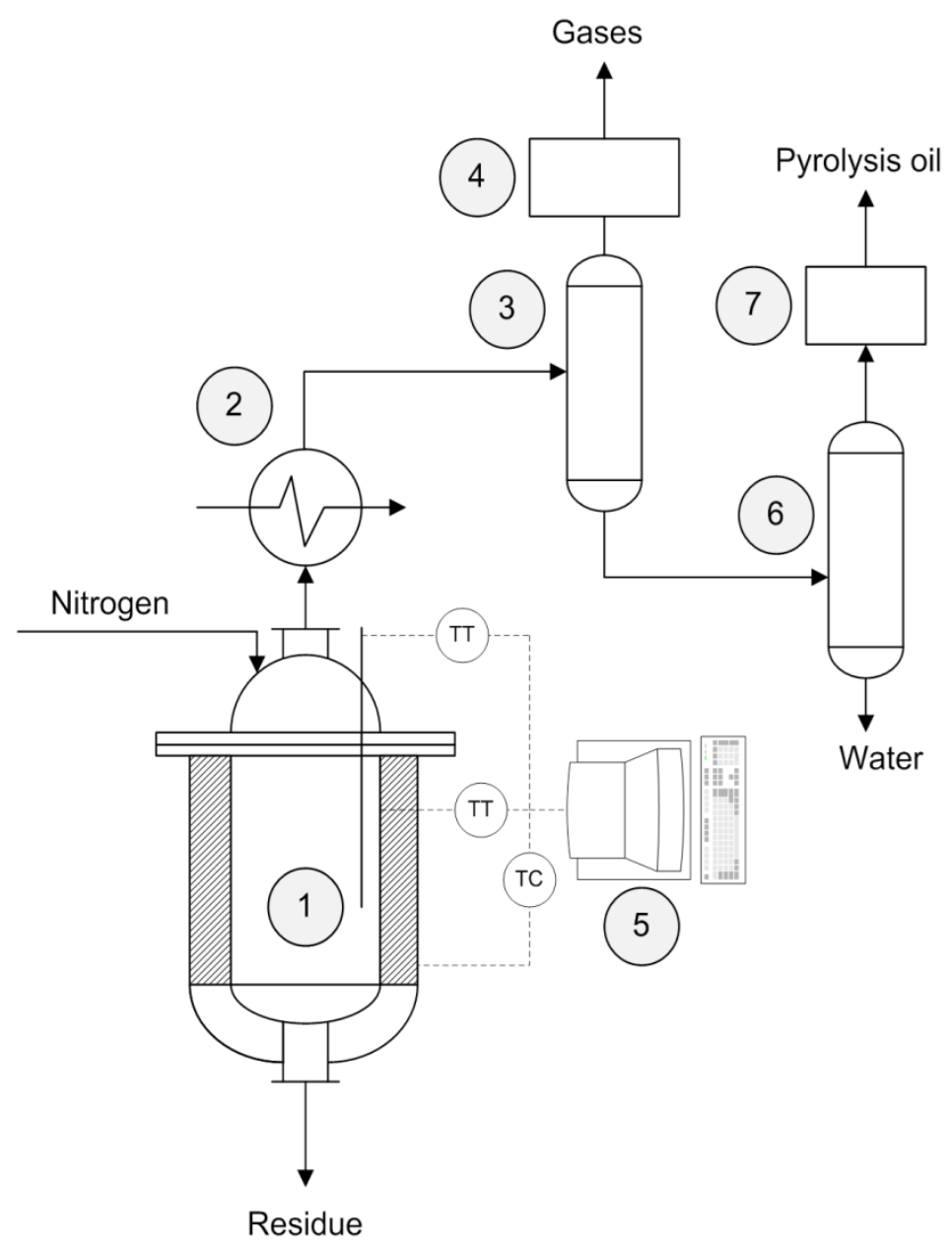

Fig. 1. Simplified layout of the laboratory scale batch pyrolysis reactor (1-electrically heated reactor vessel, 2-water cooled condenser, 3-phase separator, 4-gas flow meter, 5-computer, 6water-pyrolysis oil separator, 7-treatment with potassium-chloride). 


\section{Results and Discussion}

\subsection{Analytical pyrolysis experiments}

\subsubsection{Thermal decomposition under slow heating using HZSM-5 catalyst}

Figs. 2a, b and c show the weight (TG) curves and Figs. 2d, e and f present the weight loss rate (DTG) curves of the plastic, biomass and mixed waste samples with and without catalyst under gradual heating. Fig. 2a and d show the TG and DTG curves of plastic waste mixture both in the absence and presence of HZSM-5 catalyst using 1:1 and 10:1 sample/catalyst ratios. As the TG and DTG curves show the thermal decomposition temperature significantly decreases when HZSM-5 catalyst was mixed into the plastic waste mixture. This effect may be related to the cracking reactions catalyzed by the acid sites on the zeolite surface [19-20]. The decomposition starts at about $150{ }^{\circ} \mathrm{C}$ lower temperature and takes place at significantly lower decomposition rate, which results in a wider DTG peak. The decomposition of the whole waste sample terminates at almost the same temperature than in case of the catalyst free sample under $20{ }^{\circ} \mathrm{C} \min ^{-1}$ gradual heating. Using both waste/catalyst ratios of $1: 1$ and 10:1 the thermal stability of the plastic mixture decreases to the same extent; the DTG curves are parallel up to $360{ }^{\circ} \mathrm{C}$. It is important to note that higher catalyst feed does not result in higher decomposition rate under these experimental conditions. Using $10 \%$ catalyst, about a quarter of the plastic mixture decomposes at the same temperature range as in case of the sample without the catalyst.
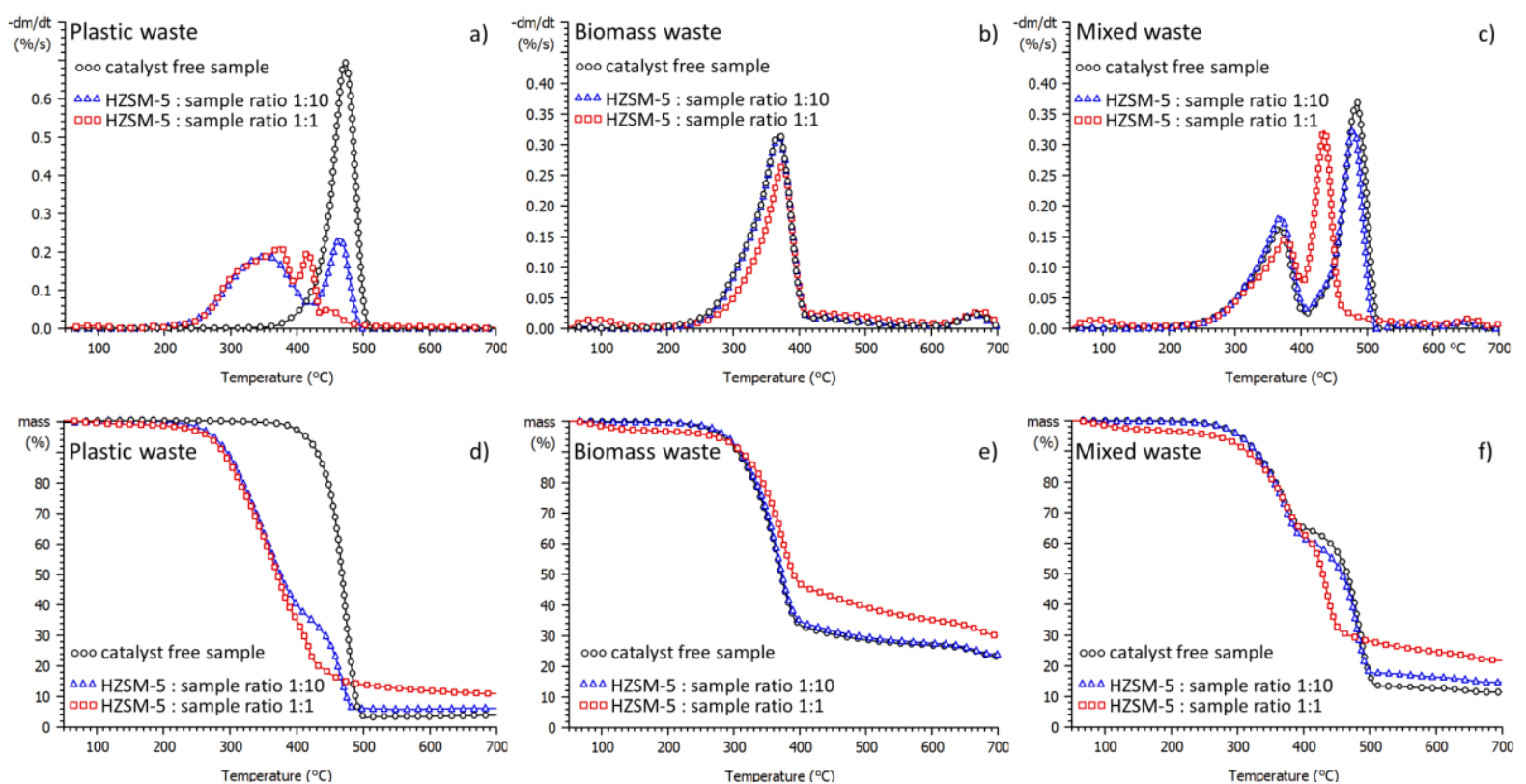

Fig. 2. TG (a-c) and DTG (d-f) curves of (a,d) plastic waste, (b,e) biomass waste, and (c,f) mixed waste samples with different loads of HZSM-5 catalyst. 
Mixing the HZSM-5 catalyst in 1:1 ratio almost the whole amount of plastic mixture decomposes at lower temperatures with the formation of about $10 \%$ char. Figs. $2 \mathrm{~b}$ and e illustrate that $10 \%$ HZSM-5 catalyst has negligible influence on the biomass decomposition, as the shape of the TG and DTG curves does not change significantly when HZSM-5 catalyst was used. However, the char formation is promoted considerably at 1:1 ratio of biomass/catalyst. Figs. $2 \mathrm{c}$ and f show the thermal decomposition of mixed waste of plastics and biomass. The sample thermally decomposes in two steps, where the first step represents the decomposition of the biomass part, while the second step stands for the decomposition of the plastic components. As the comparison of Figs. $2 \mathrm{~d}$ and $\mathrm{f}$ present, the catalytic effect of $10 \%$ HZSM-5 on the plastic decomposition is hindered when the sample contains $50 \%$ biomass. Increasing the catalyst ratio to $1: 1$, the effect of the catalyst is clearly visible: practically the whole polymer part of the mixture decomposes between 400 and $480{ }^{\circ} \mathrm{C}$ in a single fast process starting when the main biomass decomposition step has been finished. The catalytic decomposition of the polymer part of the mixture is reached the maximal rate at about $70{ }^{\circ} \mathrm{C}$ lower temperature than that of the catalyst-free mixture.

\subsubsection{Effect of catalyst on the components of the mixtures}

Figs. 3a-c present the TG, DTG and typical ion curves of plastic mixtures with and without catalyst. The shape of ion curve $\mathrm{m} / \mathrm{z} 41$ proves the pronounced effect of catalyst on the decomposition of PE and PP. The evolution profile of $\mathrm{m} / \mathrm{z}, 44$ indicates the decomposition of PET [32], which is not affected by the catalyst, as shown in Figs. 3a-c. In order to understand the hindering effect of biomass on the efficiency of HZSM-5 catalyst, the thermal decomposition of polymer mixtures containing cellulose and lignin was studied, as well. Figs. 3d-f present the TG, DTG and typical MS ion intensity curves of plastic mixtures containing 10\% HZSM-5 catalyst and various amounts of cellulose and lignin. MS ion intensity curves in Fig. $3 \mathrm{~b}$ demonstrate that $\mathrm{PE}$ and $\mathrm{PP}$ decompose in the temperature range of $230-450{ }^{\circ} \mathrm{C}$ during the catalytic pyrolysis process. 


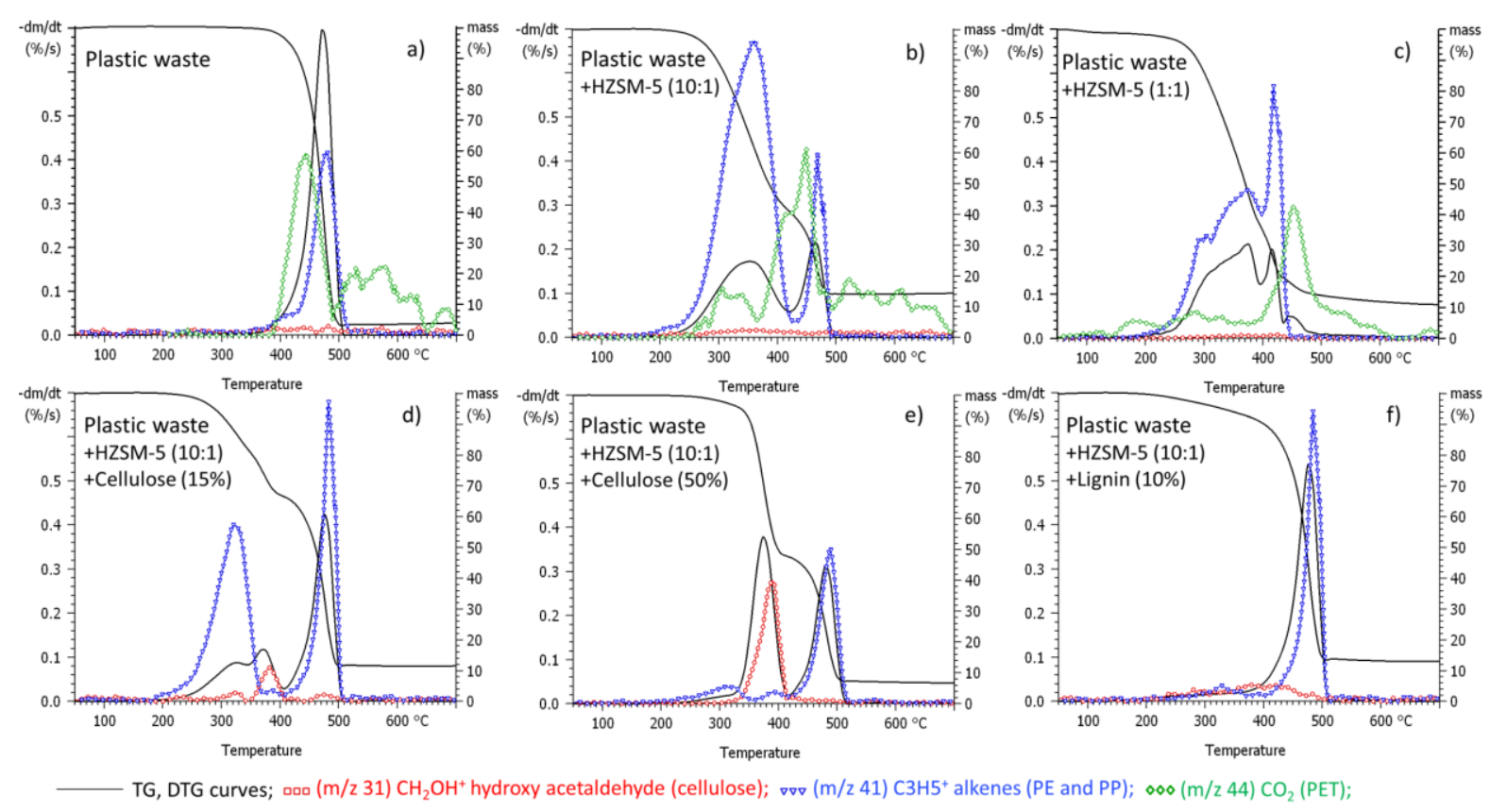

Fig. 3. TG, DTG and MS ion intensity curves of plastic mixture with various amounts of catalyst, cellulose and lignin. The intensities of the ion curves of $\mathrm{m} / \mathrm{z} 31, \mathrm{~m} / \mathrm{z}, 41$ and $\mathrm{m} / \mathrm{z}, 70$ are presented in arbitrary units in the ratios of $1: 4: 1$.

The deactivating effect of as low as $15 \%$ cellulose on the cracking properties of HZSM-5 is clearly visible (Fig. 3d). The catalytic pyrolysis of PE and PP (see $m / z 41$ ) starts at the same temperature (at around $230{ }^{\circ} \mathrm{C}$ ) as in the absence of cellulose (Fig. 3b), and the decomposition rate increases up to the point, when the cellulose content of the mixture starts to decompose (around $330{ }^{\circ} \mathrm{C}$ ) (see $\left.\mathrm{m} / \mathrm{z} 31\right)$. At this temperature the ion intensity curves of the catalytic degradation products of PP and PE fall into their baseline indicating the interrupted decomposition of the plastics. The remaining part of PE and PP decomposes at around $470{ }^{\circ} \mathrm{C}$, in the temperature range of $\mathrm{PE}$ and $\mathrm{PP}$ decomposition without catalyst. Adding 50\% cellulose to the plastics and catalyst mixture (Fig. 3e), the catalytic effect of $10 \%$ HZSM-5 is almost completely blocked. The main part of the plastic components decomposes above $420{ }^{\circ} \mathrm{C}$. Fig. $3 \mathrm{f}$ presents the thermal decomposition of plastic mixture containing $10 \%$ lignin besides the 10\% HZSM-5 catalyst. As the curves show, $10 \%$ lignin significantly hinders the catalytic activity of HZSM-5. The thermal decomposition of the total amount of plastics occurs at the same temperature as without catalyst. The hindrance of the catalytic activity can be interpreted by the effect of biomass decomposition products, which deactivates the acidic zeolite sites and delay the catalytic reactions of the plastics [19-20]. The more intensive deactivation property of lignin in comparison with cellulose can be 
explained by the fact that the thermal decomposition of lignin - thus the evolution of compounds which are able to deactivate the zeolite - starts at a lower temperature [7].

\subsubsection{Composition of the pyrolysis products}

The effect of pyrolysis temperature and waste to catalyst ratio on the composition of pyrolysis products during fast pyrolysis was studied by Py-GC/MS. The temperatures of the end of the first $\left(450{ }^{\circ} \mathrm{C}\right)$ and second $\left(550{ }^{\circ} \mathrm{C}\right)$ decomposition steps of the TG curves were selected for the pyrolysis experiments. Due to the high number of the samples, principal component analysis (PCA) has been applied to reveal correlations. Average mass spectra were generated from each pyrogram and 17 characteristic fragment and molecular ions were chosen for statistical assessment; representing aliphatics (e.g., $m / z$ 41, 43, 55, 70, 126), aromatics (e.g., $m / z$ 78, 91, 92, 106), biomass (e.g., $m / z$ 31, 60, 95, 96), and PET ( $m / z$ 297) decomposition products.

The first two principal components (Factor $1+$ Factor 2 ) describe $99 \%, 89 \%$ and $90 \%$ of the total variance in case of plastic waste (Fig. 4a), biomass waste (Fig. 4c) and mixed waste (Fig. 4e) samples, respectively. Factor 1 separates the plastic mixture samples pyrolyzed at $450{ }^{\circ} \mathrm{C}$ and $550{ }^{\circ} \mathrm{C}$ (Fig. 4a) indicating the increased amount of pyrolysis products at higher temperatures. Factor 2 separates the pure plastic samples pyrolyzed at $550{ }^{\circ} \mathrm{C}$ from the catalyst-containing samples. Fig. 4b demonstrates that using HZSM-5 catalyst increases the rate of decomposition and the relative amount of aromatic products $(\mathrm{m} / \mathrm{z}, 91,92,78)$. At 550 ${ }^{\circ} \mathrm{C}$ pyrolysis temperature the aromatization effect of HZSM-5 is more significant. Fig. 4a also involves the plastic samples pyrolyzed with cellulose and lignin additives using HZSM-5 catalyst. The position of cellulose- and lignin-containing plastic waste samples in the plot indicates the hindering effect of cellulose and lignin on the HZSM-5 catalyst.

In case of the biomass samples (Fig. 4c), Factor 1 separates the biomass sample containing $50 \%$ catalyst from other samples. The plot shows that the presence of $10 \%$ catalyst does not modify the decomposition significantly, while adding 50\% HZSM-5 catalyst changes the decomposition mechanism to a great extent, which is reflected in the increased yield of aromatic products at both temperatures (Fig. 4d). Fig. 4e shows the score plot of mixed waste samples. All samples pyrolyzed at $450{ }^{\circ} \mathrm{C}$ (except sample containing 50\% HZSM-5) and plastic-cellulose, or plastic-lignin mixtures pyrolyzed at $550{ }^{\circ} \mathrm{C}$ are situated in the upper right part of the graph indicating the similar composition of the pyrolysis products. This means that at lower temperature the catalyst is effective only if applied in higher ratio; 
furthermore the presence of cellulose or lignin is retarding the pyrolysis process. At $550{ }^{\circ} \mathrm{C}$ pyrolysis temperature, the catalyst modifies significantly the composition of the pyrolysate; the relative amount of aromatic products increased in each case (Fig. 4f).
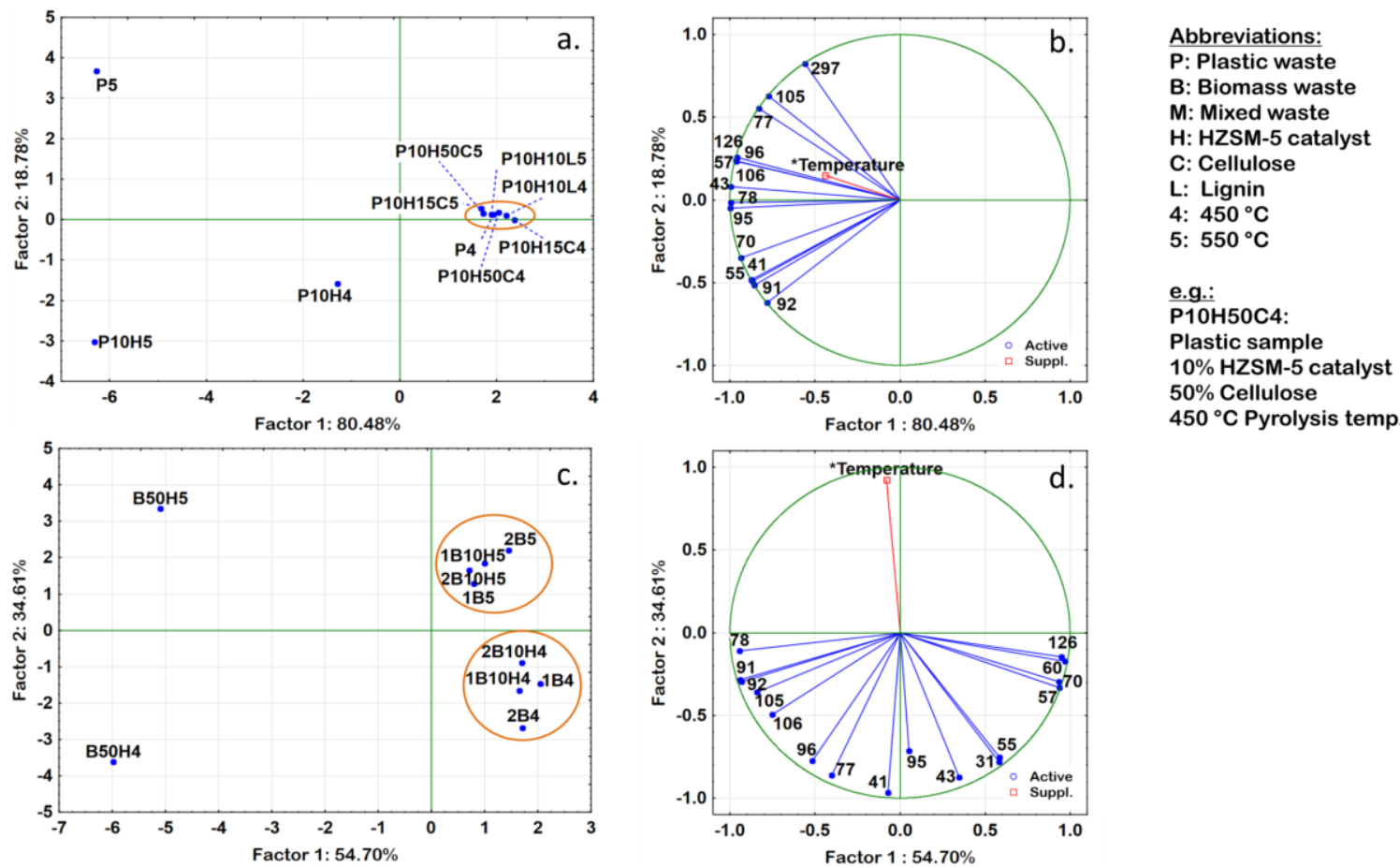

$50 \%$ Cellulose

$450{ }^{\circ} \mathrm{C}$ Pyrolysis temp.
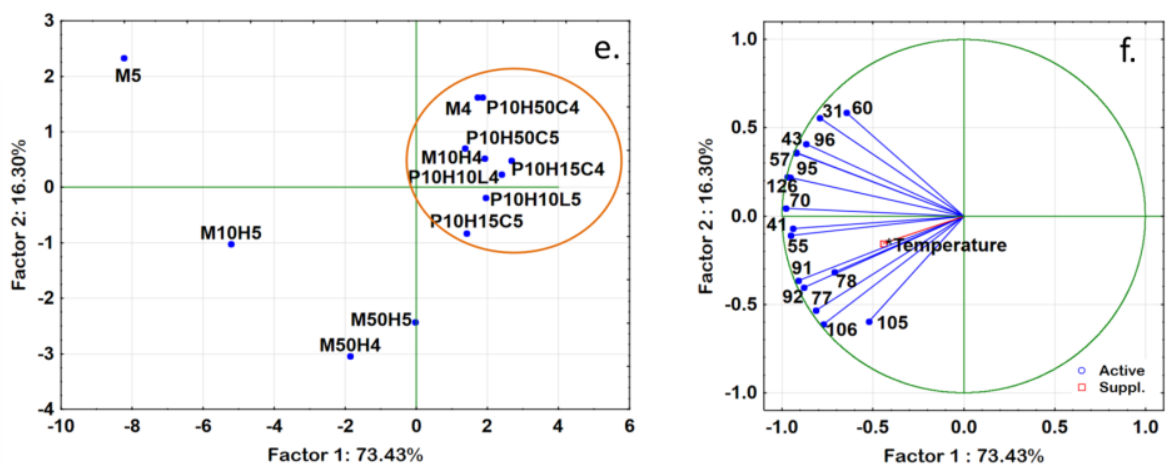

Fig. 4. (a, c, e) PCA score and (b, d, f) loading plots based on MS ion intensity data obtained from Py-GC/MS measurements of plastic waste (a, b), biomass waste (c, d) and mixed waste $(\mathrm{e}, \mathrm{f})$.

\subsection{Batch reactor experiments}

Fig. 5 illustrates the product yields obtained in larger scale pyrolysis experiments and the time requirements for the total decomposition of the samples. The temperature for the larger scale experiments was selected based on the results of analytical pyrolysis. The results of TG/MS experiments indicate the decreased decomposition rate of PE and PP at lower decomposition temperature and the unmodified decomposition of PET at $450{ }^{\circ} \mathrm{C}$ in the 
presence of HZSM-5 catalyst. Therefore, to avoid the large amount of solid residue or too large time requirements of the experiment, $550{ }^{\circ} \mathrm{C}$ pyrolysis temperature was selected for the larger scale experiments, where all main decomposition processes are terminated (see Fig.2). As the results clearly show, the time of total decomposition is significantly decreased using HZSM-5 catalyst, which implies the higher rate of decomposition reactions. The results indicate that the decreased decomposition rate at lower decomposition temperature observed under gradual heating (TG/MS experiments) does not appear as a drawback using higher isothermal pyrolysis temperature. It is also well known [33], that zeolite catalysts (e.g. ZSM5 , y-zeolite, FCC, $\beta$-zeolite, etc.) support the ionic initiated decomposition, which needs considerably lower activation energy than that of the free radical initiated one.

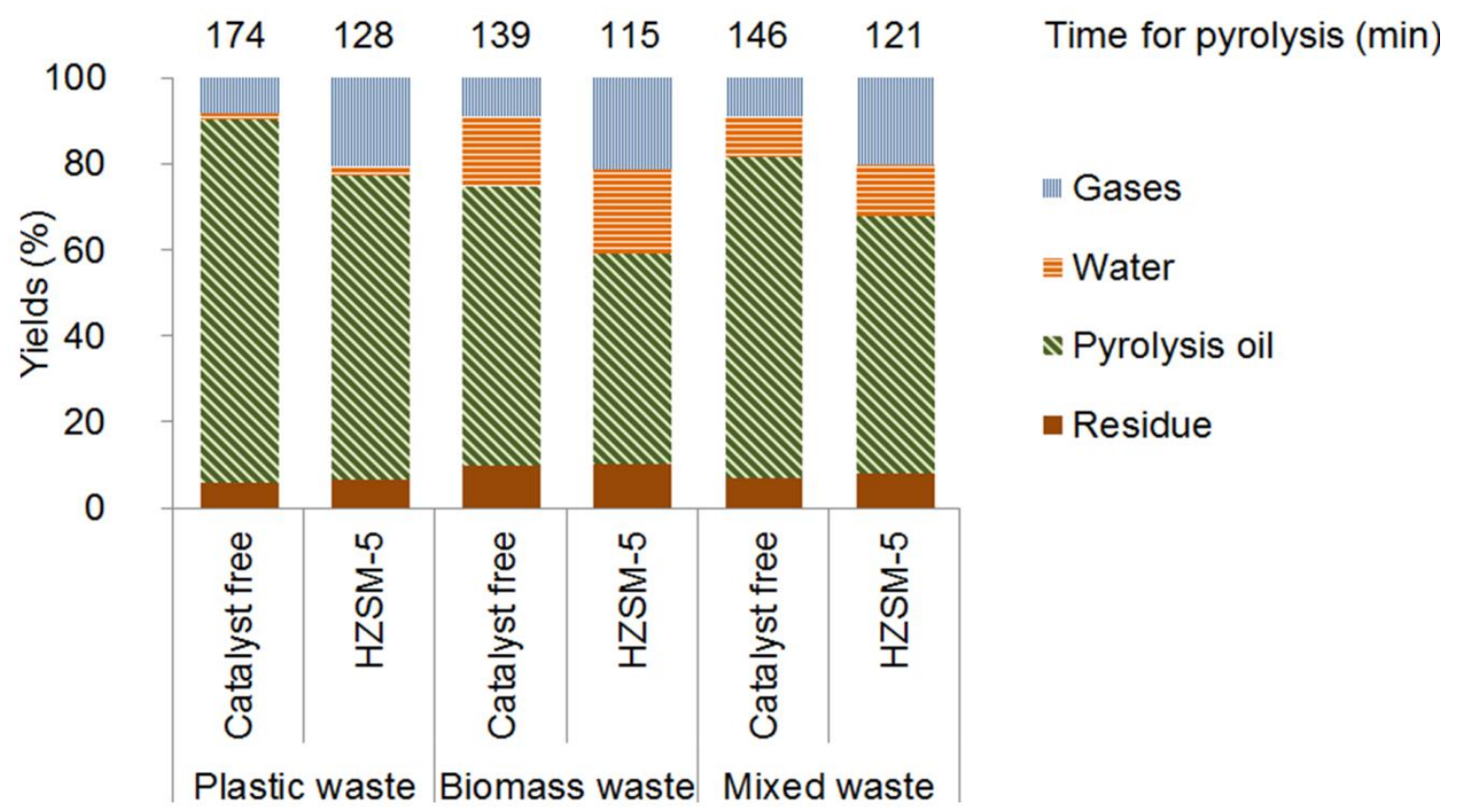

Fig. 5. Product yields (wt $\%$ ) in the batch reactor. (The gas yield was determined by difference.)

It is also clear that significantly higher yield of gases was measured from each sample when HZSM-5 catalyst was applied than without the catalyst. The gas yield was 8.4, 9.1 and 9.1\% without catalyst in case of plastic, biomass and mixed samples, which increased to $18.8,19.5$ and $18.3 \%$ applying HZSM-5 catalyst, respectively. HZSM-5 catalyst has relatively small sized pore structure, high surface area (in the current work over $300 \mathrm{~g} / \mathrm{m}^{2}$ ), and widely applied as cracking catalyst that favors the formation of smaller molecules [30, 34]. The long polymer chains of the samples are able to decompose primarily on the catalyst surface; 
however, the smaller fragment molecules can be further cracked inside the catalyst micropores.

The pyrolysis oil yield was $84.5,65.1$ and $74.7 \%$ without catalyst in case of plastic, biomass and mixed samples, which decreased to 70.6, 49.1 and 59.8\% applying HZSM-5 catalyst, respectively. On the other hand, less time was needed for the total pyrolysis using HZSM-5 catalyst, which refers to the faster decomposition of the raw materials. HZSM-5 catalyst induced severe degradation that led to increased gas yields and decreased pyrolysis oil yield. The polymer pyrolysis lead to more oil than biomass pyrolysis, and the thermo-catalytic pyrolysis of each mixture resulted in much less oil than catalyst free pyrolysis. Without catalyst 5.7, 9.6 and $6.7 \%$ black solid residue was deposited on the internal wall of the reactor during pyrolysis of plastics, biomass and mixed waste, respectively. Slightly higher residue yield was measured in the thermo-catalytic experiments $6.5 \%$ (plastics), $10.0 \%$ (biomass) and $7.8 \%$ (mixed). Owing to the oxygen content of these samples, $1.4-19.5 \%$ water formed in the pyrolysis reactions. The water is undesirable in the pyrolysis oil because it deteriorates the advantageous properties of products, e.g., decreases the heating value, which leads to lower price of the pyrolysis oil; or causes serious corrosion problems during transportation, storage and application. As the data demonstrates, the pyrolysis oil from plastic waste had the lowest water content; $1.4 \%$ without catalyst and $2.3 \%$ with HZSM-5 catalyst. It is also well known, that significant amount of water can be formed from the $-\mathrm{OH}$ groups of each polymeric component of biomass (cellulose, hemicelluloses, and lignin) during pyrolysis [5]. In the current work, the water yield was 16.2 and 19.5\% regarding thermal and thermo-catalytic pyrolysis of biomass, while $9.5 \%$ (without catalyst) and $12.2 \%$ (with HZSM-5 catalyst) concerning plastic-biomass mixture. In all cases the water yield increased somewhat in the presence of HZSM-5 catalyst. It can be concluded that the water content of the oil should be removed before use. Nevertheless, the promoted scission of the oxygen-containing functional groups in the presence of catalyst means that the heating value of the dried pyrolysis oil increases due to the reduced oxygen-content. 
Table 2. Volume $\%$ of the permanent gases obtained from batch pyrolysis and the total gas yield.

\begin{tabular}{lcccccc}
\hline \multirow{2}{*}{ Gases } & \multicolumn{2}{c}{ Plastic waste } & \multicolumn{2}{c}{ Biomass waste } & \multicolumn{2}{c}{ Mixed waste } \\
\cline { 2 - 7 } & Catalyst free & HZSM-5 & Catalyst free & HZSM-5 & Catalyst free & HZSM-5 \\
\hline $\mathrm{H}_{2}$ & 0.0 & 0.0 & 3.8 & 3.8 & 1.5 & 0.9 \\
$\mathrm{CO}$ & 8.2 & 7.9 & 16.4 & 20.6 & 13.6 & 16.9 \\
$\mathrm{CO}_{2}$ & 6.4 & 5.6 & 14.9 & 11.4 & 9.6 & 7.0 \\
Methane & 4.8 & 7.0 & 7.7 & 7.1 & 7.6 & 7.6 \\
$\mathrm{C}_{2}$ & 16.6 & 10.9 & 8.5 & 10.7 & 10.1 & 10.6 \\
Other & 64.0 & 68.6 & 48.7 & 46.4 & 57.6 & 57.0 \\
Total gas & 8.4 & 20.7 & 9.1 & 21.5 & 9.1 & 20.1 \\
yield (\%) & & & & & &
\end{tabular}

The composition of the permanent gases formed during batch pyrolysis experiments was analyzed by GC (Table 2). During pyrolysis of plastic waste, no hydrogen was produced. It is well known, that the catalyst free pyrolysis of polyethylene and polypropylene results exclusively in hydrocarbons [35]; while from PET significant amount of carbon oxides are formed by pyrolysis [32]. In plastic waste (PE/PP/PET) pyrolysis, the main effect of the HZSM-5 catalyst was the slightly increased $\mathrm{CO} / \mathrm{CO}_{2}$ ratio (from 1.28 to 1.40 ) due to the coke deposition, which enhances the transformation of $\mathrm{CO}_{2}$ to $\mathrm{CO}$ at the applied temperature. However, $\mathrm{CO} / \mathrm{CO}_{2}$ ratio increased more in the pyrolysis gas of biomass (from 1.10 to 1.80 ) and during pyrolysis of the mixed waste sample (from 1.42 to 2.42). Methane increased mainly from the plastic waste, while $\mathrm{C}_{2}$ hydrocarbons increased to a higher degree from biomass and decreased in case of plastic waste.

The main properties of the pyrolysis oil are shown in Table 3. The composition of the liquid fraction was measured by GC-FID. Both the waste material and the catalyst affected the decomposition reactions, therefore notable differences could be observed among the products formed during the catalyst free and the thermo-catalytic pyrolysis. Due to the catalyst activity, the concentration of aromatics increased largely in the oil of thermo-catalytic pyrolysis of plastic waste. Nevertheless, the amount of aromatic compounds increased to a reduced extent by thermo-catalytic pyrolysis of biomass-containing plastic waste samples indicating that the cellulose and lignin components of the waste decrease the HZSM-5 catalyst activity. The higher heating value of pyrolysis oils was between 29.8 and $42.6 \mathrm{MJ} / \mathrm{kg}$, which is lower than that of the petroleum based heating oil, but high enough for energy generation. It is also well known that biomass mixing in the raw material results in 
significantly decreased heating value, which is the consequence of the increased ratio of oxygen containing products and the lower proportion of heteroatom free hydrocarbons in the pyrolysis oil [36]. Both the decreased density and the increased volatility data resulting in decreased boiling point ranges (Table 3 ) demonstrate the C-C cracking property of HZSM-5 catalyst. The data present that the boiling point corresponding to each volume range decreased in the pyrolysis oil prepared in presence of the catalyst. It means that the volume of both naphta $\left(25-200{ }^{\circ} \mathrm{C}\right)$ and kerosene $\left(150-250{ }^{\circ} \mathrm{C}\right)$ fractions were higher in case of thermocatalytic pyrolysis. Pour points support the observation that the catalyst decreased the average molecular weight and promoted the isomerization of products. Polyethylene represents $40 \%$ of the plastic mixture, which produces long-chain alkanes and alkenes during pyrolysis. Apparently, these products are isomerized and aromatized via several steps in the presence of HZSM-5 catalyst. The reactions are outlined in Scheme 1 [37].

Scheme 1.<smiles>[R][R2]C[CH+]CCC[R]</smiles>

Cyclization/Aromatization

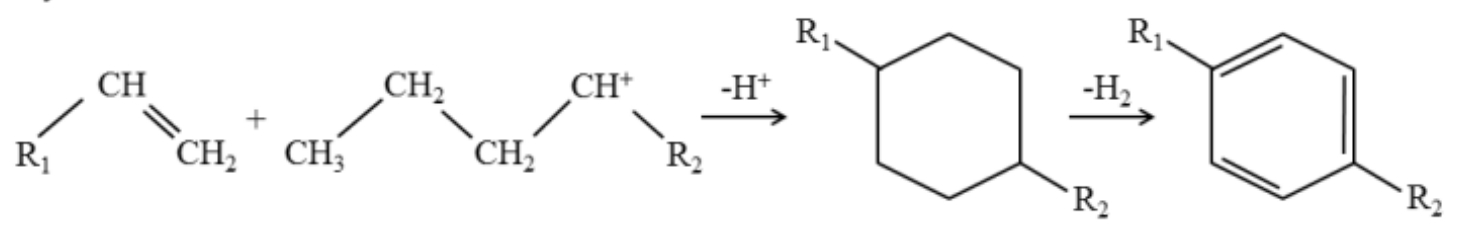


Table 3. Main properties of pyrolysis oil obtained from batch pyrolysis

\begin{tabular}{|c|c|c|c|c|c|c|}
\hline \multirow{2}{*}{ Pyrolysis oil } & \multicolumn{2}{|c|}{ Plastic waste } & \multicolumn{2}{|c|}{ Biomass waste } & \multicolumn{2}{|c|}{ Mixed waste } \\
\hline & Catalyst free & HZSM-5 & Catalyst free & HZSM-5 & Catalyst free & HZSM-5 \\
\hline Density, $\mathrm{g} / \mathrm{cm}^{3}$ & 0.814 & 0.795 & 0.831 & 0.818 & 0.823 & 0.809 \\
\hline Non-aromatic products, Area \% & 94.8 & 80.5 & 94.3 & 87.6 & 92.6 & 83.9 \\
\hline Aromatic products (hydrocarbons), Area $\%$ & 5.2 & 19.5 & 5.7 & 12.4 & 7.4 & 16.1 \\
\hline Benzene, \% & 2.6 & 9.2 & 0.8 & 6.1 & 2.3 & 8.0 \\
\hline Toluene, \% & 1.7 & 8.0 & 0.7 & 3.4 & 1.4 & 4.6 \\
\hline Styrene, \% & 0.4 & 0.6 & 1.3 & 0.5 & 1.2 & 1.0 \\
\hline Xylenes, \% & 0.3 & 1.0 & 1.8 & 1.1 & 1.6 & 1.2 \\
\hline Cumene, \% & 0.2 & 0.6 & 1.1 & 1.3 & 1.0 & 1.3 \\
\hline $\mathrm{IBP},{ }^{\circ} \mathrm{C}$ & 25 & 22 & 26 & 24 & 24 & 25 \\
\hline $10 \%,{ }^{\circ} \mathrm{C}$ & 82 & 73 & 85 & 81 & 84 & 78 \\
\hline $50 \%,{ }^{\circ} \mathrm{C}$ & 164 & 147 & 179 & 173 & 171 & 159 \\
\hline $90 \%,{ }^{\circ} \mathrm{C}$ & 259 & 241 & 268 & 264 & 263 & 257 \\
\hline $\mathrm{FBP},{ }^{\circ} \mathrm{C}$ & 307 & 295 & 303 & 308 & 299 & 304 \\
\hline Pour point, ${ }^{\circ} \mathrm{C}$ & -15 & -21 & -11 & -14 & -14 & -18 \\
\hline $\mathrm{HHV}, \mathrm{MJ} / \mathrm{kg}$ & 42.5 & 42.6 & 29.8 & 30.1 & 34.7 & 34.5 \\
\hline Water content, ppm & $<10$ & $<10$ & $<10$ & $<10$ & $<10$ & $<10$ \\
\hline
\end{tabular}




\section{Conclusions}

Microgram-scale analytical pyrolysis and laboratory batch pyrolysis led to complementary results in studies of thermo-catalytic pyrolysis of biomass and plastic mixtures using HZSM5. The HZSM-5 catalyst significantly decreased the decomposition temperature of hydrocarbon polymers, while it did not modify the decomposition of PET. The catalyst modified significantly the composition of the pyrolyzate of the investigated waste mixtures, as a consequence of the isomerization and aromatization activity of the catalyst in both analytical and laboratory scale batch reactor experiments. Comparing to batch thermocatalytic pyrolysis, higher catalyst feeds should have been applied in analytical pyrolysis methods to observe analogous catalytic effect due to the lower contact time of the pyrolysis vapor and the catalyst. Using 50\% catalyst and $550{ }^{\circ} \mathrm{C}$ pyrolysis temperature in Py-GC/MS experiments led to the formation of high amount of aromatics due to the catalytic processes. The TG/MS studies revealed that mixing 15\% cellulose only hindered, but adding 50\% cellulose or $10 \%$ lignin blocked the catalytic activity of HZSM-5 on hydrocarbon polymers under slow heating. In batch thermo-catalytic pyrolysis experiments, the production of aromatic compounds from biomass-containing plastic waste samples was reduced comparing to plastic waste samples confirming that the cellulose and lignin components of the waste lowered the HZSM-5 catalyst activity. The statistical evaluation (PCA) of the Py-GC/MS results confirmed the hindering effect of biomass and its components on the catalytic activity of HZSM-5 catalyst under fast heating as well. The cracking activity of the catalyst was demonstrated by the decreased density and the lower boiling point ranges of all the thermocatalytic pyrolysis oils deriving of the plastics, biomass, and their mixture in batch pyrolysis experiments.

\section{Acknowledgements}

This work was supported by the National Research Development and Innovation Office (NKFIH) [TÉT_13_DST-1-2014-0003].

The short version of the paper was presented at ICAE2016 on Oct 8-11, Beijing, China. This paper is a substantial extension of the short version of the conference paper.

\section{Abbreviations}


FBP Final boiling point

IBP Initial boiling point

HHV Higher heating value

TG curve weight of the sample as a function of temperature or time

DTG curve weight loss rate as a function of temperature or time

MSW Municipal solid waste

PCA Principal component analysis

WFD Waste Framework Directive

\section{References}

[1] Ripa M, Fiorentino G, Giani H, Clausen A, Ulgiati S. Refuse recovered biomass fuel from municipal solid waste. A life cycle assessment. Appl. Energy 2017;186:211-225. http://dx.doi.org/10.1016/j.apenergy.2016.05.058

[2] Kabir G, Hameed B H. Recent progress on catalytic pyrolysis of lignocellulosic biomass to high grade bio-oil and bio-chemicals. Renew. Sust. Energy Rev. 2017; In Press. http://dx.doi.org/10.1016/j.rser.2016.12.001

[3] Miandad R, Barakat M A, Aburiazaiza A S, Rehan M. Nizami A S. Catalytic pyrolysis of plastic waste: A review. Process. Saf. Environ. Prot. 2016;102:822-838.

http://dx.doi.org/10.1016/j.psep.2016.06.022

[4] Sharuddin S D A, Abnisa F, Daud W M A W, Aroua M K. A review on pyrolysis of plastic wastes. Energy Convers. Manage. 2016;115:308-326.

http://dx.doi.org/10.1016/j.enconman.2016.02.037

[5] Chen D, Yin L, Wang H, He P. Reprint of: Pyrolysis technologies for municipal solid waste: A review. Waste Manage. 2015;37:116-136.

http://dx.doi.org/10.1016/j.wasman.2015.01.022

[6] Dickerson T, Soria J. Catalytic fast pyrolysis: A review. Energy 2013;6:514-538. http://dx.doi.org/10.3390/en6010514

[7] Yang H., Yan R., Chen H., Lee D.H. Zheng C. Characteristics of hemicellulose, cellulose and lignin pyrolysis, Fuel 2007;86:1781-1788.

http://dx.doi.org/10.1016/j.fuel.2006.12.013 
[8] Blazsó M. Polyaromatization in common synthetic polymers at elevated temperatures, J. Anal. Appl. Pyrol. 1993; 25-35.

https://doi.org/10.1016/0165-2370(93)80030-4

[9] Sajdak M, Muzyka R, Hrabak J, Słowik K. Use of plastic waste as a fuel in the copyrolysis of biomass. Part I: The effect of the addition of plastic waste on the process and products. J. Anal. Appl. Pyrolysis. 2014;107:267-275.

http://dx.doi.org/10.1016/j.jaap.2014.03.011

[10] Sajdak M, Słowik K. Use of plastic waste as a fuel in the co-pyrolysis of biomass: Part II. Variance analysis of the co-pyrolysis process. J. Anal. Appl. Pyrolysis. 2014;109:152-158. http://dx.doi.org/10.1016/j.jaap.2014.07.001

[11] Sajdak M, Muzyka R, Hrabak J, Słowik K. Use of plastic waste as a fuel in the copyrolysis of biomass. Part III: Optimisation of the co-pyrolysis process. J. Anal. Appl. Pyrolysis. 2015;112:298-305.

http://dx.doi.org/10.1016/j.jaap.2015.01.008

[12] Brebu M, Yanik J, Uysal T, Vasile C. Thermal and catalytic degradation of grape seeds/polyethylene waste mixtures. Cellulose Chem. Technol. 2014; 48 (7-8): 665-674.

[13] Hudec P. FCC catalyst - Key element in refinery technology, 45th Int. Pet. Conf., June 13, 2011.http://www.vurup.sk/sites/default/files/downloads/46_ft_hudec-fcc.pdf

[14] Muradov Z. N. $\mathrm{CO}_{2}$-free production of hydrogen by catalytic pyrolysis of hydrocarbon fuel, Energy Fuel 1998; 12(1):41-48.

http://pubs.acs.org/doi/full/10.1021/ef9701145

[15] Guicai Liu, Yanfen Liao, Shaode Guo, Xiaoqian Ma, Chengcai Zeng, Jie Wu,Thermal behavior and kinetics of municipal solid waste during pyrolysis and combustion process, Appl. Therm. Eng. 98 (2016) 400-408.

10.1016/j.applthermaleng.2015.12.067

[16] Hernandez M D R, Gomez A, Garcia A N, Agullo J, Marcilla A. Effect of the temperature in the nature and extension of the primary and secondary reactions in the thermal and HZSM-5 catalytic pyrolysis of HDPE. Appl. Catal. A: Gen. 2007;317:183-194.

http://dx.doi.org/10.1016/j.apcata.2006.10.017 
[17] Lorenzetti C, Conti R, Fabbri D, Yanik J. A comparative study on the catalytic effect of H-ZSM5 on upgrading of pyrolysis vapors derived from lignocellulosic and proteinaceous biomass. Fuel 2016; 166:446-452.

http://dx.doi.org/10.1016/j.fuel.2015.10.051

[18] Marcilla A, Gomez-Siurana A, Berenguer D. Study of the early deactivation in pyrolysis of polymers in the presence of catalysts. J. Anal. Appl. Pyrolysis. 2007;79:443-449.

http://dx.doi.org/10.1016/j.jaap.2007.02.002

[19] Beom-Sik K, Young-Min K, Hyung Won L, Jungho J, Do Heui K, Sang-Chul J. Chuichi W, Young-Kwon P. Catalytic co-pyrolysis of cellulose and thermoplastics over HZSM-5 and HY. ACS Sustain. Chem. Eng. 2016;4:1354-1363.

http://dx.doi.org/10.1021/acssuschemeng.5b01381

[20] Marcilla A, Beltran M I , Hernandez F, Navarro R. HZSM-5 and HUSY deactivation during the catalytic pyrolysis of polyethylene. Appl. Catal. A: Gen. 2004;278:37-43. http://dx.doi:10.1016/j.apcata.2004.09.023

[21] Marcilla A, Gomez-Siurana A, Odjo A O, Navarro R, Berenguer D. Characterization of vacuum gas oil-low density polyethylene blends by thermogravimetric analysis. Polym. Degrad. Stab. 2008;93:723-730.

http://dx.doi:10.1016/j.polymdegradstab.2007.12.010

[22] Muhammad C, Onwudili J A, Williams P T. Thermal degradation of real-World waste plastics and simulated mixed plastics in a two-stage pyrolysis-catalysis reactor for fuel production. Energy Fuels. 2015;29:2601-2609.

http://dx.doi:10.1021/ef502749h

[23] Zhang B, Zhong Z, Ding K, Song Z. Production of aromatic hydrocarbons from catalytic co-pyrolysis of biomass and high density polyethylene: Analytical Py-GC/MS study. Fuel 2015;139:622-628.

http://dx.doi.org/10.1016/j.fuel.2014.09.052

[24] Dorado C, Mullen C A, Boateng A A. H-ZSM5 catalyzed co-pyrolysis of biomass and plastics. ACS Sustain. Chem. Eng. 2014;2:301-311.

http://dx.doi.org/10.1021/sc400354g 
[25] Liu G, Wright M M, Zhao Q, Brown R C. Catalytic fast pyrolysis of duckweed: Effects of pyrolysis parameters and optimization of aromatic production. J. Anal. Appl. Pyrolysis. 2015;112:29-36.

http://dx.doi.org/10.1016/j.jaap.2015.02.026

[26] Dorado C, Mullen C A, Boateng A A. Origin of carbon in aromatic and olefin products derived from HZSM-5catalyzed co-pyrolysis of cellulose and plastics via isotopic labeling. Appl. Catal. B: Environ. 2015;162:338-345.

http://dx.doi.org/10.1016/j.apcatb.2014.07.006

[27] Jong-Ryeol K, Jik-Hyun Y, Dae-Won P. Catalytic recycling of the mixture of polypropylene and polystyrene. Polym. Degrad. Stab. 2002;76:61-67.

http://dx.doi.org/10.1016/S0141-3910(01)00266-X

[28] Ates F, Miskolczi N, Borsodi N. Comparision of real waste (MSW and MPW) pyrolysis in batch reactor over different catalysts. Part I: Product yields, gas and pyrolysis oil properties. Bioresour. Technol. 2013;133:443-454.

http://dx.doi.org/10.1016/j.biortech.2013.01.112

[29] Miskolczi N, Ates F, Borsodi N. Comparison of real waste (MSW and MPW) pyrolysis in batch reactor over different catalysts. Part II: Contaminants, char and pyrolysis oil properties. Bioresour. Technol. 2013;144:370-379.

http://dx.doi.org/10.1016/j.biortech.2013.06.109

[30] López A, Marco I, Caballero B M, Adrados A, Laresgoiti M F. Deactivation and regeneration of ZSM-5 zeolite in catalytic pyrolysis of plastic wastes. Waste Manag. 2011;31:1852-1858.

http://dx.doi:10.1016/j.wasman.2011.04.004

[31] Wold S, Esbensen K, Geladi P. Principal component analysis. Chemom. Intell. Lab.Syst. $1987 ; 2: 37-52$.

http://dx.doi.org/10.1016/0169-7439(87)80084-9

[32] Yoshioka T, Grause G, Eger C, Kaminsky W, Okuwaki A. Pyrolysis of poly(ethylene terephthalate) in a fluidised bed plant. Polym. Deg. Stab. 2004; 86(3) 499-504. http://dx.doi.org/10.1016/j.polymdegradstab.2004.06.001

[33] Bhatia S. Zeolite Catalysts: Principles and Applications. CRC Press. 1990. 
ISBN: 0-8493-5628-8.

[34] Marcilla A, Gómez-Siurana A, Valdés F: Catalytic pyrolysis of LDPE over H-beta and HZSM-5 zeolites in dynamic conditions: Study of the evolution of the process. J. Anal. Appl. Pyrolysis. 2007; 79:433-442.

https://doi.org/10.1016/j.jaap.2006.09.006

[35] Ahmad I, Khan M I, Khan H, Ishaq M, Tariq R, Gul K, Ahmad W. Pyrolysis study of polypropylene and polyethylene into premium oil products. Int. J. Green Energy. 2015;12:663-671.

http://dx.doi.org/10.1080/15435075.2014.880146

[36] Boumanchar I, Chhiti Y, Alaoui F E M, El Ouinani A, Sahibed-Dine A, Bentiss F, Jama C, Bensitel M. Effect of materials mixture on the higher heating value: Case of biomass, biochar and municipal solid waste. Waste Manag. 2017; 61:78-86. https://doi.org/10.1016/j.wasman.2016.11.012

[37] Miskolczi N. Kinetic model of the chemical and catalytic recycling of waste polyethylene into fuels, in Scheirs J, and Kaminsky W.(Eds.) Feedstock recycling and pyrolysis of waste plastics, John Wiley \& Sons, Ltd, 2006; 225-247.

ISBN-13: 978-0-470-02152-1, ISBN-10: 0-470-02152-7 